\title{
Oxidation of Caffeine by Permanganate Ion in Perchloric and Sulfuric Acids Solutions: A Comparative Kinetic Study
}

\author{
Ahmed Fawzy ${ }^{1,2}$, Ishaq A. Zaafarany ${ }^{1}$, Khalid S. Khairou ${ }^{1}$, Layla S. Almazroai ${ }^{1}$, \\ Tahani M. Bawazeer ${ }^{1}$, Badriah A. Al-Jahdali ${ }^{1}$ \\ ${ }^{1}$ Chemistry Department, Faculty of Applied Science, Umm Al-Qura University, Makkah, Saudi Arabia \\ ${ }^{2}$ Chemistry Department, Faculty of Science, Assiut University, Assiut, Egypt

\section{Email address:} \\ afsaad13@yahoo.com (A. Fawzy), iazaafarany@uqu.edu.sa (I. A. Zaafarany),kskhairou@uqu.edu.sa (K. S. Khairou), \\ lsmazroai@uqu.edu.sa (L. S. Almazroai),tmbawazeer@uqu.edu.sa (T. M. Bawazeer), bajahdali@uqu.edu.sa (B. A. Al-Jahdali)
}

\section{To cite this article:}

Ahmed Fawzy, Ishaq A. Zaafarany, Khalid S. Khairou, Layla S. Almazroai, Tahani M. Bawazeer, Badriah A. Al-Jahdali. Oxidation of Caffeine by Permanganate Ion in Perchloric and Sulfuric Acids Solutions: A Comparative Kinetic Study. Science Journal of Chemistry. Vol. 4, No. 2, 2016, pp. 19-28. doi: 10.11648/j.sjc.20160402.12

Received: April 5, 2016; Accepted: April 12, 2016; Published: May 3, 2016

\begin{abstract}
The kinetics of oxidations of caffeine by permanganate ion in both perchloric and sulfuric acids solutions have been investigated spectrophotometrically at a constant ionic strength of $1.0 \mathrm{~mol} \mathrm{dm}^{-3}$ and at $25^{\circ} \mathrm{C}$. In both acids, the reactiontime curves were obtained with a sigmoid profile suggesting an autocatalytic effect caused by $\mathrm{Mn}$ (II) ions formed as a reaction product. Both catalytic and non-catalytic processes were determined to be first order with respect to the permanganate ion and caffeine concentrations, whereas the orders with respect to $\left[\mathrm{H}^{+}\right]$and $[\mathrm{Mn}(\mathrm{II})]$ were found to be less than unity. Variation of either ionic strength or dielectric constant of the medium had no significant effect on the oxidation rates. Spectroscopic studies and Michaelis-Menten plots showed no evidence for the formation of intermediate complexes in both acids suggesting that the reactions point towards the outer-sphere pathway. The reactions mechanism adequately describing the kinetic results was proposed. In both acids, the main oxidation products of caffeine were identified as 1,3,7-trimethyluric acid. Under comparable experimental conditions, the oxidation rate of caffeine in perchloric acid was slightly higher than that in sulfuric acid. The constants involved in the different steps of the reactions mechanism have been evaluated. With admiration to the rate-limiting step of these reactions, the activation parameters have been evaluated and discussed.
\end{abstract}

Keywords: Caffeine, Oxidation, Permanganate, Acid, Kinetics, Mechanism

\section{Introduction}

Alkaloids are a group of naturally occurring chemical compounds that act on a diversity of metabolic systems in humans and other animals. They are produced by a large variety of organisms including bacteria, fungi, plants, and animals. Alkaloids have a wide range of pharmacological activities including antimalarial, antiasthma, anticancer, cholinomimetic, antibacterial, psychotropic and stimulant activities [1-3]. Among the significant alkaloids is caffeine which is a member of the purine alkaloid group of metabolites widely found in the leaves and fruits of many types of plants [4]. Caffeine (1,3,7-trimethylxanthine) is one of the most popular and commercially important plant derived purine alkaloids. It is also one of the most commonly used legal pharmaceutical drugs throughout the world, being present in foods, beverages, including coffee, tea, soft drinks, energy drinks and medicines [5]. It is a key additive to at least 150 other products that are available currently in the market. Caffeine is a central nervous system and metabolic stimulant $[6,7]$, used to reduce physical fatigue and to prevent or treat drowsiness. It has the desired effect of delaying/preventing sleep and also improves performance during sleep deprivation [8]. In athletes, moderate doses of caffeine can improve sprint [9], stamina, endurance [10], and team sports performance [11], but the improvements are usually limited. At normal doses, caffeine improves memory in learning and sleep deprived activities, but has both beneficial and harmful effects on the working memory depending on the nature of the task [12]. Caffeine has been 
the subject of extensive research in recent years [13] because of its wide spread occurrence in nature [4], their longstanding history of human consumption, possibly since the Stone Age [14], its physiological effects, and its applicability in foods, drugs and cosmetics [5].

Oxidation reactions are very important in organic synthesis. Among the important oxidizing agents, permanganate ion is widely used in the oxidations of many organic compounds in neutral, alkaline and acidic media [1525]. The mechanism of oxidation reactions by permanganate ion is governed by $\mathrm{pH}$ of the medium [26]. During oxidation by permanganate, it is evident that the $\mathrm{Mn}(\mathrm{VII})$ in permanganate is reduced to various oxidation states in acid, alkaline and neutral media. In acid media, permanganate ion $\left(\mathrm{MnO}_{4}{ }^{-}\right)$can exist in several different forms, $\mathrm{HMnO}_{4}$, $\mathrm{H}_{2} \mathrm{MnO}_{4}{ }^{+}, \mathrm{HMnO}_{3}$, and $\mathrm{Mn}_{2} \mathrm{O}_{7}$ depending on the nature of the reductant. The oxidant has been assigned with an innersphere and an outer-sphere mechanism pathways in their redox reactions [27, 28].

A literature survey revealed that there are very few reports [29-31] describing the mechanism of oxidation of caffeine, which may be important from a metabolic point of view. Furthermore, caffeine oxidation could lead to novel bioprocesses to produce commercially important derivatives which may be applicable in cosmetics and medicines. In view of the foregoing aspects, we prompted to undertake the present investigation of the kinetics and mechanism of oxidations of caffeine by permanganate ion as the most efficient and eco-friendly oxidizing agent in different acid media. The objectives of the present study are to check the reactivity of caffeine towards permanganate ion in acid media, and to propose the oxidation mechanism of such drug to understand its mode of action in biological systems.

\section{Experimental}

\subsection{Materials}

All chemicals used in this work were of reagent grade and their solutions were prepared by dissolving the required amounts of the samples in doubly distilled water. The stock solution of caffeine was prepared by dissolving the sample (Sigma-Aldrich) in doubly distilled water. Potassium permanganate freshly solution was prepared and standardized as reported earlier [32]. Sodium perchlorate and acetic acid were used to attain the required ionic strength and dielectric constant of the reactions medium, respectively.

\subsection{Kinetic Measurements}

The kinetic measurements were followed under pseudofirst order conditions where caffeine was existed in a large excess over that of permanganate. Initiation of the reactions were done by mixing the formerly thermostatted solutions of permanganate and caffeine that also contained the required amounts of the acid and $\mathrm{NaClO}_{4}$. The courses of the reactions were followed by monitoring the decay in the absorbance of permanganate as a function of time at its absorption maximum $(\lambda=525 \mathrm{~nm})$, whereas the other constituents of the reaction mixtures did not absorb considerably at this wavelength. The absorption measurements were done in a temperature-controlled Shimadzu UV-VIS-NIR-3600 double-beam spectrophotometer. Application of Beer's law was verified for permanganate concentrations at $\lambda=525 \mathrm{~nm}$, and the molar extinction coefficient was found to be $\varepsilon=2230$ $\pm 45 \mathrm{dm}^{3} \mathrm{~mol}^{-1} \mathrm{~cm}^{-1}$.

The orders of the reactions with respect to the reactants were determined from the slopes of the $\log k_{\mathrm{s}}$ and $\log k_{\mathrm{f}}$ versus $\log$ (concentration) plots, where $k_{\mathrm{s}}$ and $k_{\mathrm{f}}$ refer to the pseudo-first order rate constants of the slow (induction) and fast (auto-acceleration) periods, by varying the concentrations of caffeine and acids, in turn, while keeping other conditions constant.

\section{Results}

\subsection{Stoichiometry and Product Characterization}

Reaction mixtures containing various amounts of permanganate ion and caffeine at constant $\left[\mathrm{H}^{+}\right]$, ionic strength, and temperature were allowed to react for $24 \mathrm{~h}$ in closed vessels for completion of the oxidation reactions. The unconsumed [permanganate] was determined spectrophotometrically at $525 \mathrm{~nm}$. The results indicated that four moles of permanganate are consumed by five mole of caffeine to yield the oxidation products as shown in the following equation,

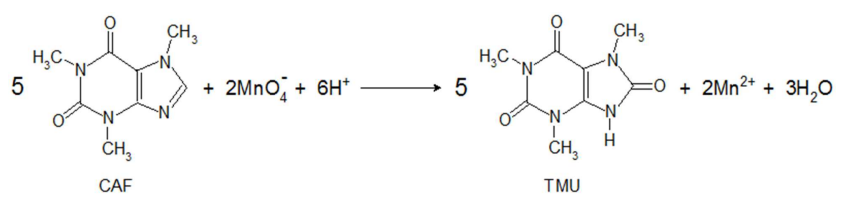

where CAF and TMU denotes caffeine and its oxidation product, 1,3,7-trimethyluric acid which was identified by HPLC analysis. Similar oxidation product of caffeine was reported earlier [32].

\subsection{Spectral Changes}

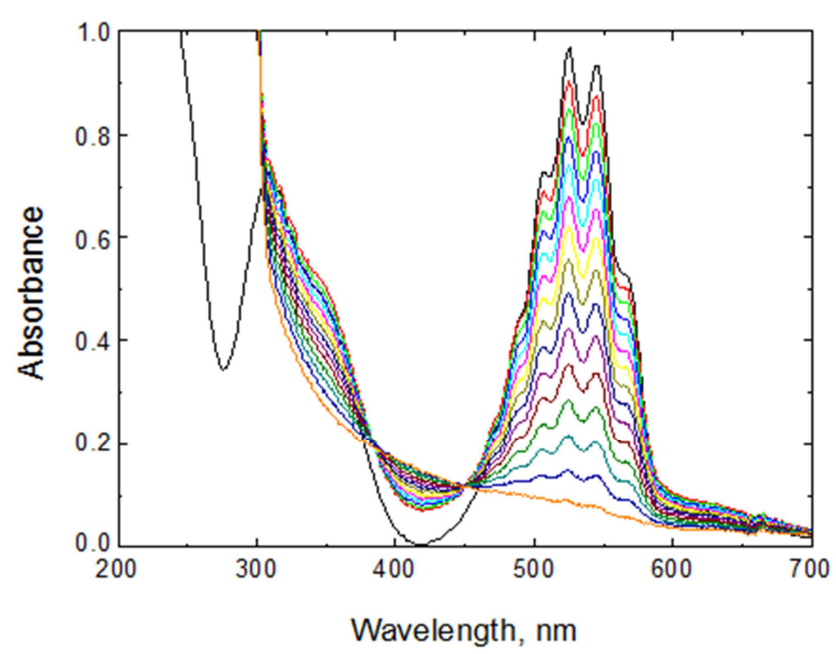

(a) 


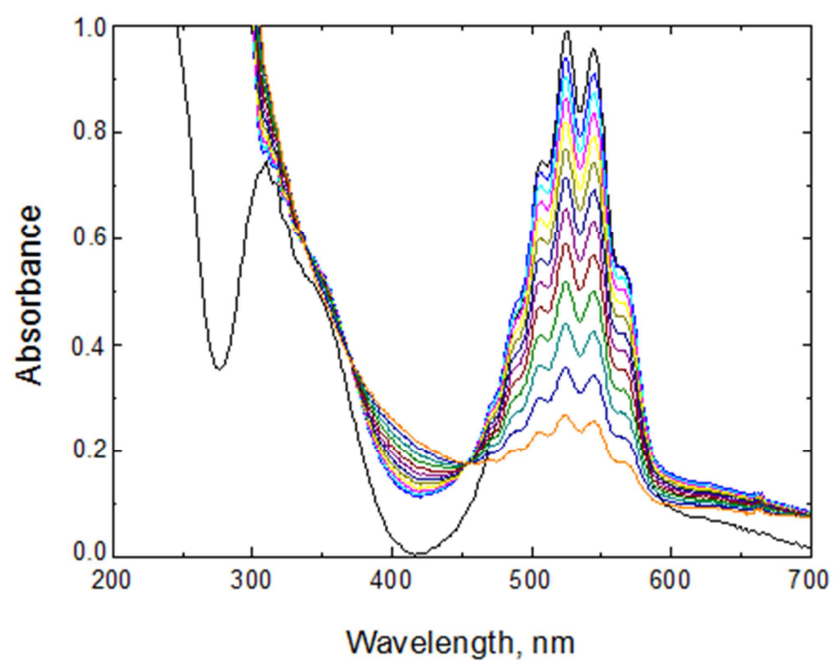

(b)

Figure 1. Spectral changes during the oxidations of caffeine by permanganate ion in: (a) perchloric, and (b) sulfuric acid solutions. [CAF] $=1.0 \times 10^{-2},\left[\mathrm{MnO}_{4}^{-}\right]=4.0 \times 10^{-4},\left[\mathrm{H}^{+}\right]=0.5$ and $I=1.0 \mathrm{~mol} \mathrm{dm} \mathrm{m}^{-3}$ at $25^{\circ} \mathrm{C}$. Scanning time intervals $=2.0 \mathrm{~min}$.

The spectral scans during the oxidation of caffeine by permanganate ion in perchloric and sulfuric acids solutions are shown in Figure $=1$ (a) and (b), respectively. It was shown that there are gradual disappearance of permanganate band at its absorption maximum $(\lambda=525 \mathrm{~nm})$. Figure 1 shows also a simultaneous appearance of a new band at a wavelength of $418 \mathrm{~nm}$ with two isosbestic points located in the region of $370-450 \mathrm{~nm}$.
The reaction time curve describing the double-stage time courses during the oxidation of caffeine by permanganate ion in, for example, perchloric acid medium is illustrated in Figure 2. The curve was sigmoid where the initial stage was slow, followed by an increase in the oxidation rate over longer time periods. The pseudo-first order rate constants, $k_{\mathrm{s}}$ and $k_{\mathrm{f}}$, were calculated using non-linear least-squares fitting to the first order dependence of the absorbance versus time plots. The rate constants were the main values of at least two kinetic measurements. The rate constants were reproducible to within $3-4 \%$.

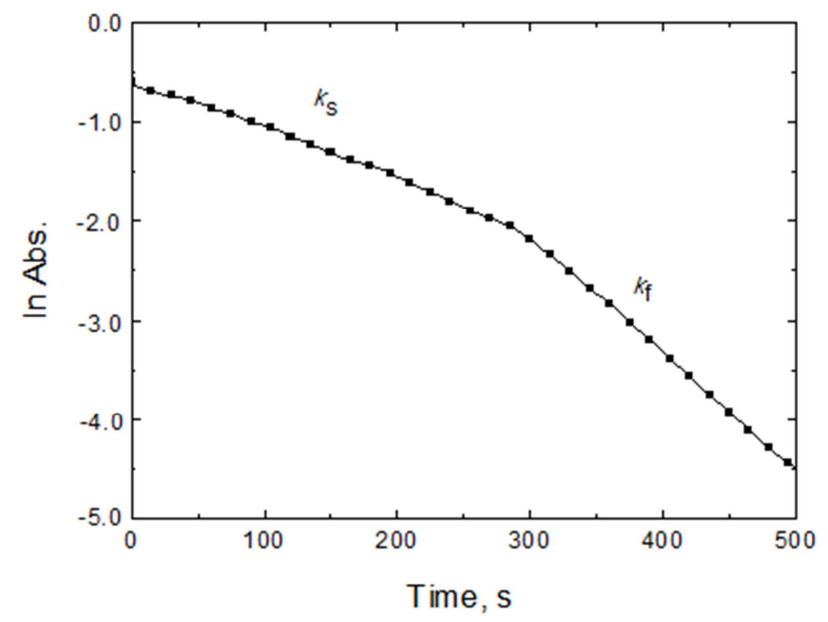

Figure 2. Reaction-time curve for the oxidation of caffeine by permanganate ion in perchloric acid medium. $[\mathrm{CAF}]=0.01,\left[\mathrm{MnO}_{4}^{-}\right]=4.0 \times 10^{-4},\left[\mathrm{H}^{+}\right]=$ 0.1 , and $I=1.0 \mathrm{~mol} \mathrm{dm}^{-3}$ at $25^{\circ} \mathrm{C}$.

\subsection{Reaction-Time Curves}

Table 1. Effect of variation of $\left[\mathrm{MnO}_{4}^{-}\right],[\mathrm{CAF}],\left[\mathrm{H}^{+}\right]$and I on the pseudo-first order rate constants in the oxidations of caffeine by permanganate ion in perchloric and sulfuric acids solutions at $25^{\circ} \mathrm{C}$.

\begin{tabular}{|c|c|c|c|c|c|c|c|}
\hline \multirow{2}{*}{$\begin{array}{l}1^{4}\left[\mathrm{MnO}_{4}^{-}\right] \\
\left(\mathrm{mol} \mathrm{dm}^{-3}\right)\end{array}$} & \multirow{2}{*}{$\begin{array}{l}10^{2}[\mathrm{CAF}] \\
\left(\mathrm{mol} \mathrm{dm}^{-3}\right)\end{array}$} & \multirow{2}{*}{$\begin{array}{l}{\left[\mathrm{H}^{+}\right]} \\
\left(\mathrm{mol} \mathrm{dm}^{-3}\right)\end{array}$} & \multirow{2}{*}{$\begin{array}{l}I \\
\left(\mathrm{~mol} \mathrm{dm}^{-3}\right)\end{array}$} & \multicolumn{2}{|l|}{ Perchloric } & \multicolumn{2}{|l|}{ Sulfuric } \\
\hline & & & & $10^{3} k_{\mathrm{s}}\left(\mathrm{s}^{-1}\right)$ & $10^{3} k_{\mathrm{f}}\left(\mathrm{s}^{-1}\right)$ & $10^{3} k_{\mathrm{s}}\left(\mathrm{s}^{-1}\right)$ & $10^{3} k_{\mathrm{f}}\left(\mathrm{s}^{-1}\right)$ \\
\hline 2.0 & 1.0 & 0.6 & 1.0 & 21.2 & 32.0 & 19.1 & 28.3 \\
\hline 4.0 & 1.0 & 0.6 & 1.0 & 22.1 & 32.6 & 18.9 & 27.2 \\
\hline 6.0 & 1.0 & 0.6 & 1.0 & 23.9 & 34.1 & 18.4 & 26.3 \\
\hline 8.0 & 1.0 & 0.6 & 1.0 & 21.9 & 32.5 & 20.2 & 27.1 \\
\hline 10.0 & 1.0 & 0.6 & 1.0 & 22.4 & 31.7 & 18.0 & 27.9 \\
\hline 4.0 & 0.2 & 0.6 & 1.0 & 5.5 & 7.3 & 4.5 & 6.7 \\
\hline 4.0 & 0.6 & 0.6 & 1.0 & 13.1 & 17.9 & 12.0 & 16.2 \\
\hline 4.0 & 1.0 & 0.6 & 1.0 & 22.1 & 32.6 & 18.9 & 27.2 \\
\hline 4.0 & 1.4 & 0.6 & 1.0 & 30.4 & 43.8 & 25.2 & 37.1 \\
\hline 4.0 & 1.8 & 0.6 & 1.0 & 36.2 & 54.3 & 33.0 & 46.0 \\
\hline 4.0 & 1.0 & 0.1 & 1.0 & 6.2 & 9.1 & 5.2 & 7.2 \\
\hline 4.0 & 1.0 & 0.3 & 1.0 & 14.7 & 20.2 & 12.1 & 17.0 \\
\hline 4.0 & 1.0 & 0.5 & 1.0 & 22.1 & 32.6 & 18.9 & 27.2 \\
\hline 4.0 & 1.0 & 0.7 & 1.0 & 29.7 & 42.8 & 25.6 & 35.7 \\
\hline 4.0 & 1.0 & 0.9 & 1.0 & 38.2 & 51.7 & 31.5 & 42.9 \\
\hline 4.0 & 1.0 & 0.6 & 1.0 & 22.1 & 32.6 & 18.9 & 27.2 \\
\hline 4.0 & 1.0 & 0.6 & 1.3 & 23.1 & 33.6 & 20.2 & 28.2 \\
\hline 4.0 & 1.0 & 0.6 & 1.6 & 22.9 & 33.1 & 18.4 & 29.1 \\
\hline 4.0 & 1.0 & 0.6 & 1.9 & 21.0 & 31.2 & 19.2 & 28.9 \\
\hline 4.0 & 1.0 & 0.6 & 2.2 & 22.4 & 31.9 & 21.7 & 29.1 \\
\hline
\end{tabular}

Experimental error $\pm 3 \%$ 


\subsection{Rate Dependence on Permanganate Ion Concentration}

Permanganate ion oxidant was varied in the concentration range $(2.0-10.0) \times 10^{-4} \mathrm{~mol} \mathrm{dm}^{-3}$ while the rest of the reactant concentrations were kept constant. Both $\mathrm{pH}$ and temperature were also kept constant. Variation of the initial concentration of permanganate showed almost no influence on the pseudo-first order rate constants $\left(k_{\mathrm{s}} \& k_{\mathrm{f}}\right)$ as listed in Table 1, indicating first order dependence with respect to permanganate ion concentration.

\subsection{Rate Dependence on Caffeine Concentration}

The pseudo-first order rate constants were measured at various concentrations of caffeine keeping others constant. Plots of $k_{\mathrm{s}}$ and $k_{\mathrm{f}}$ versus [CAF] were found to be linear passing through origin in both perchloric and sulfuric acid solutions as shown in Figure 3 confirming first order dependence with respect to caffeine concentration.

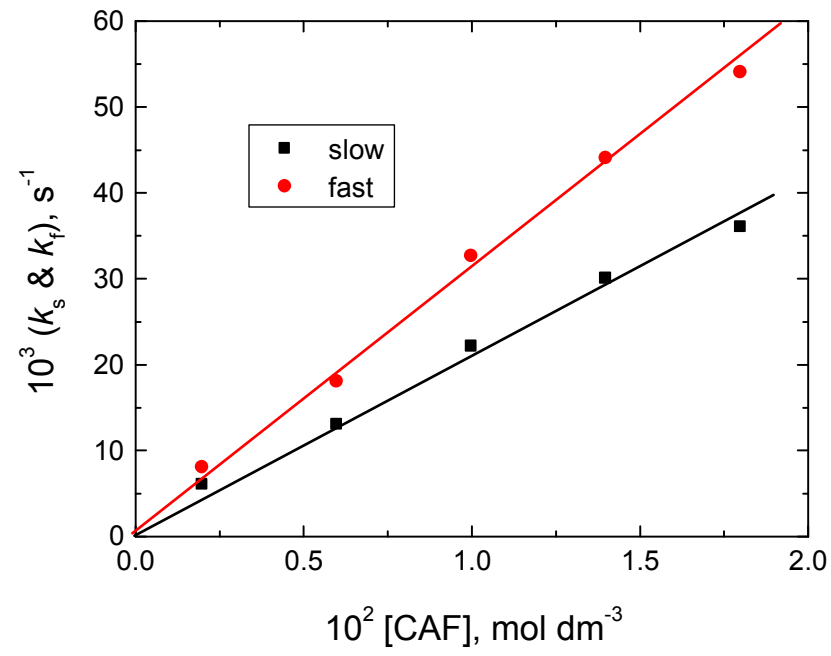

(a)

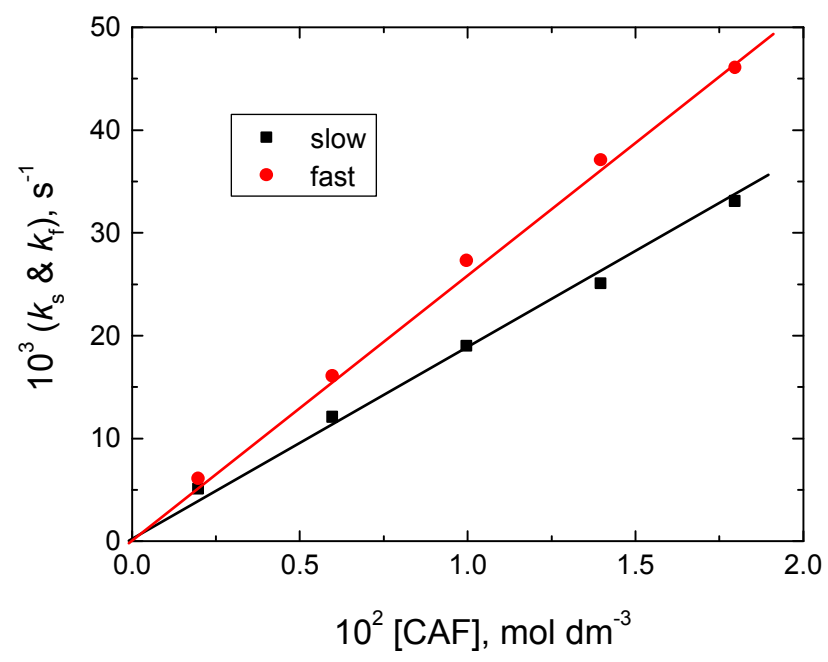

(b)

Figure 3. Plots of the pseudo-first order rate constants $\left(k_{s}\right.$ and $\left.k_{f}\right)$ versus $[C A F]$ in the oxidations of caffeine by permanganate ion in: (a) perchloric and, (b) sulfuric acid solutions. $\left[\mathrm{MnO}_{4}^{-}\right]=4.0 \times 10^{-4},\left[\mathrm{H}^{+}\right]=0.5$ and $\mathrm{I}=1.0$ $m o l d m^{-3}$ at $25^{\circ} \mathrm{C}$.

\subsection{Rate Dependence on Acids Concentration}

The influence of both perchloric and sulfuric acid on the rates was investigated by varying the hydrogen ion concentration in the range: $0.1-0.9 \mathrm{~mol} \mathrm{dm}^{-3}$, keeping all other reactants concentrations constant. Plots of $\log k_{\mathrm{s}}$ and $\log k_{\mathrm{f}}$ versus $\log \left[\mathrm{H}^{+}\right]$were also linear with slopes ranging between 0.84 and 0.78 in both acids, Figure 4, suggesting that the orders of reactions with respect to [acid] were less than unity.

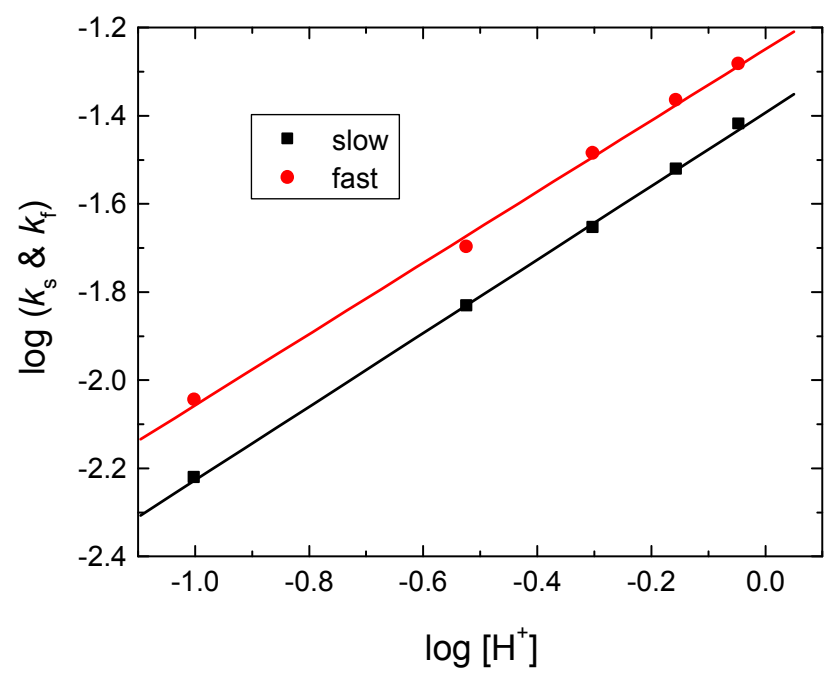

(a)

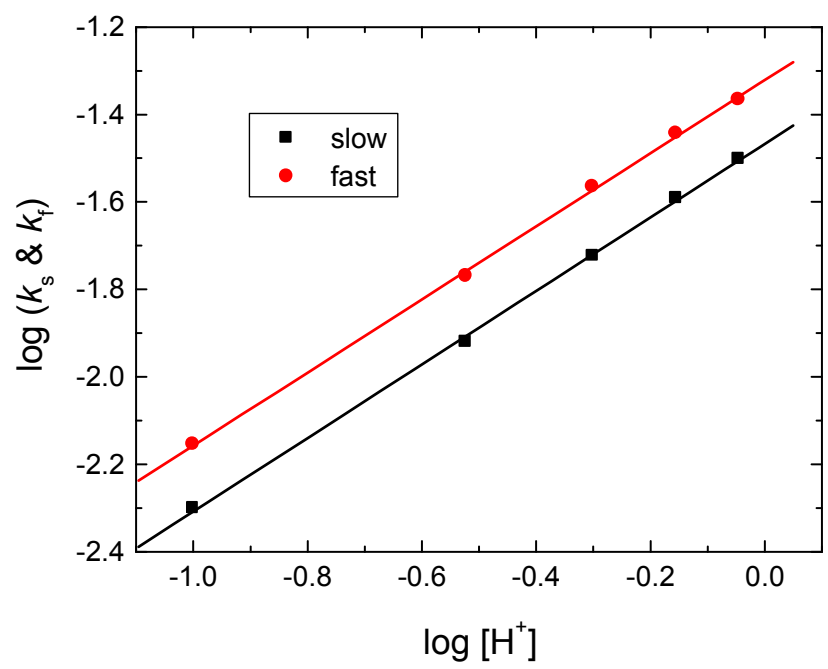

(b)

Figure 4. Plots of $\log k_{s}$ and $\log k_{f}$ versus $\log \left[\mathrm{H}^{+}\right]$in the oxidations of caffeine by permanganate ion in: (a) perchloric and, (b) sulfuric acid solutions. $\left[\mathrm{MnO}_{4}^{-}\right]=4.0 \times 10^{-4},[\mathrm{CAF}]=0.01$ and $\mathrm{I}=1.0 \mathrm{~mol} \mathrm{dm}{ }^{-3}$ at $25^{\circ} \mathrm{C}$.

\subsection{Effect of Ionic Strength and Dielectric Constant}

The ionic strength effect was studied by varying the concentration of $\mathrm{NaClO}_{4}$ in the reactions media at constant concentrations of permanganate, caffeine and acid. It was 
found that variation in ionic strength did not affect the rates as observed from the data listed in Table 1.

The effect dielectric constant $(D)$ was also studied by varying the acetic acid - water content in the reaction mixture with all other conditions being kept constant. The data clearly revealed that the rate constants did not significantly affected by the decrease in dielectric constant of the solvent mixture; i.e. increase in acetic acid content.

\subsection{Rate Dependence on Initially Added Manganese(II) Product}

The initially added product, Mn(II), was studied in the concentration range of $(1.0-9.0) \times 10^{-4}$ moldm $^{-3}$, while keeping the reactant concentrations and all other conditions constant. As the $\mathrm{Mn}$ (II) concentration increases the reaction rate also increases with a sigmoid profile for the reactiontime curves were obtained, indicating autocatalytic activity of $\mathrm{Mn}(\mathrm{II})$. The orders with respect to $[\mathrm{Mn}(\mathrm{II})]$ were less than unity, as shown in Figure 5(a).

\subsection{Rate Dependence on Added Fluoride Ions}

The influence added $\mathrm{F}^{-}$ions was examined by addition of its salt to the reaction medium in the concentration range of $(1.0-9.0) \times 10^{-4}$ moldm $^{-3}$, while keeping all other conditions constant. The experimental results indicated that the reaction rate was found to decrease upon addition of $\mathrm{F}^{-}$ions as shown in Figure 5(b).

\subsection{Effect of Temperature}

The rates of the reactions were carried out at four different temperatures between 288 and $318 \mathrm{~K}$ at constant concentrations of the reactants and other conditions being constant. The results indicate that the rate constants increased with rise in temperature. The activation parameters of the second order rate constant $\left(k_{2}\right)$ are calculated using Eyring and Arrhenius plots and are listed in Table 2.

\subsection{Polymerization Study}

To check the existence of free radicals in the reactions under investigations, the reactions mixtures were mixed with identified quantities of acrylonitrile monomer and kept for 6 hours in an inert atmosphere. On diluting the reactions mixtures with methanol, heavy white precipitates of polymers were formed, indicating the intervention of free radicals in the present reactions. Blank experiments with either caffeine or permanganate alone with acrylonitrile did not induce any polymerization under the same condition as those induced for the reaction mixture.

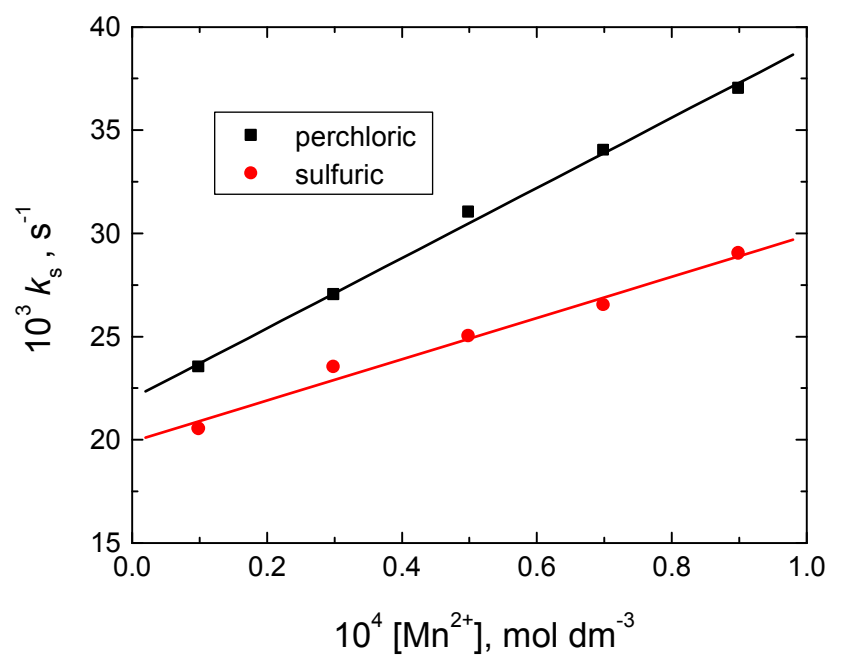

(a)

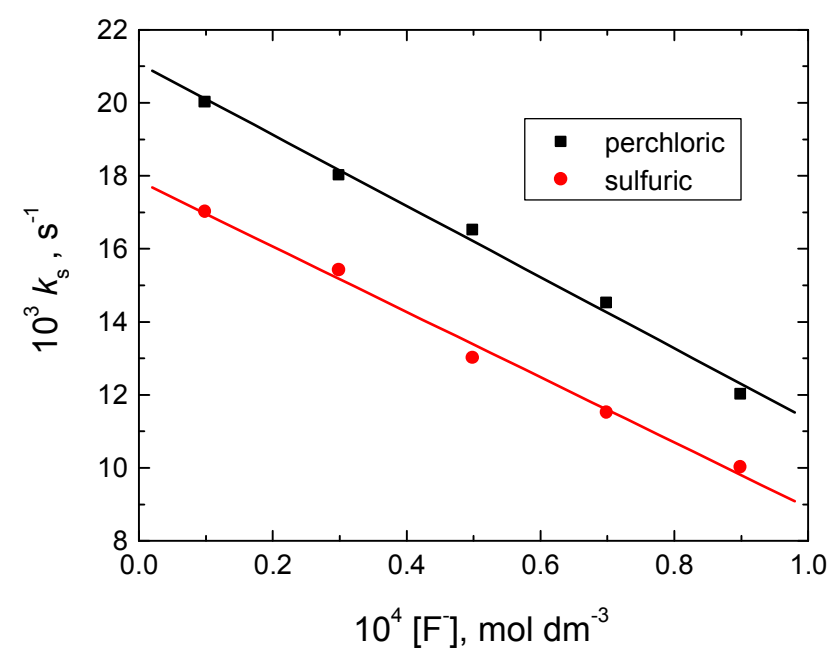

(b)

Figure 5. Effect of added: (a) manganese(II) and, (b) fluoride ions on the pseudo-first order rate constant in the oxidations of caffeine by permanganate ion in perchloric and sulfuric acids solutions. $\left[\mathrm{MnO}_{4}^{-}\right]=4.0$ $x 10^{-4},[C A F]=0.01$ and $I=1.0 \mathrm{~mol} \mathrm{dm}^{-3}$ at $25^{\circ} \mathrm{C}$.

Table 2. Activation parameters of the second order rate constant $\left(k_{2}\right)$ in the oxidations of caffeine by permanganate ion in perchloric and sulfuric acids solutions. $\left[\mathrm{MnO}_{4}^{-}\right]=4.0 \times 10^{-4},[\mathrm{CAF}]=0.01,\left[\mathrm{H}^{+}\right]=0.5$ and $\mathrm{I}=1.0 \mathrm{~mol} \mathrm{dm}$.

\begin{tabular}{|c|c|c|c|c|}
\hline Acid & $\Delta S^{\neq}, \mathrm{J} \mathrm{mol}^{-1} \mathrm{~K}^{-1}$ & $\Delta H^{\ddagger}, \mathrm{kJ} \mathrm{mol}^{-1}$ & $\Delta G_{298}^{f}, \mathrm{~kJ} \mathrm{~mol}^{-1}$ & $E_{\mathrm{a}}^{\neq}, \mathrm{kJ} \mathrm{mol}^{-1}$ \\
\hline Perchloric & 81.60 & 63.12 & 38.80 & 65.07 \\
\hline Sulfuric & 67.33 & 65.71 & 45.64 & 68.89 \\
\hline
\end{tabular}

\section{Discussion}

Spectral changes in both perchloric and sulfuric acid solutions, illustrated in Figure 1(a, b), show gradual disappearance of permanganate ion at its absorption maximum as the reactions proceed suggesting reduction of permanganate ion by caffeine substrate. It can be also observed that there are no rise and fall in the absorption spectra above $\lambda=600 \mathrm{~nm}$ which may be considered as an evidence against complex formation between oxidant and substrate. A further evidence against complex formation was 
the Michaelis-Menten [33] plots of $1 / k_{\mathrm{s}}$ against $1 /[\mathrm{CAF}]$ which gave straight lines passing through the origin (Figure 6). Similar behavior was reported elsewhere [34, 35].

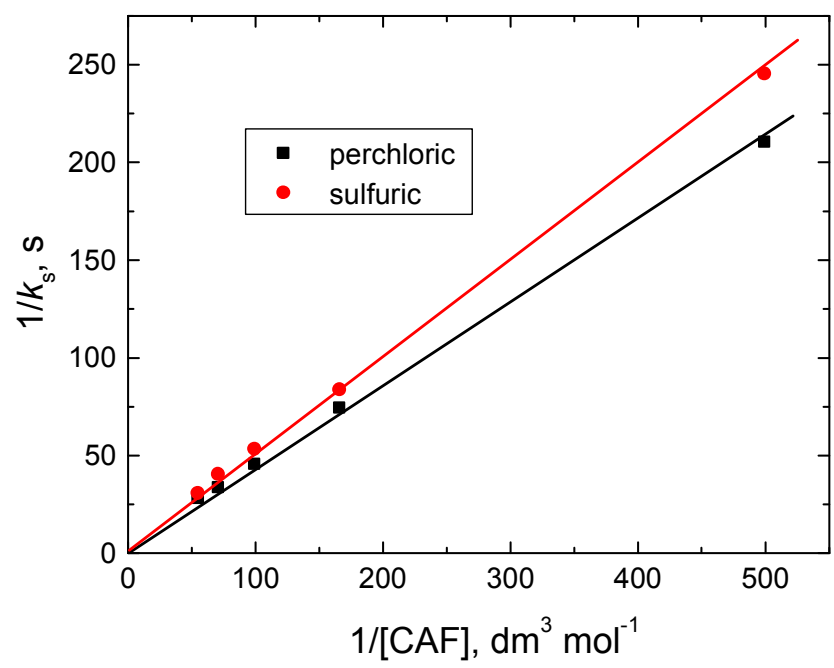

Figure 6. Plots of $1 / k_{s}$ versus $1 /[C A F]$ the oxidation of caffeine by permanganate ion in perchloric acids medium. $[\mathrm{CAF}]=0.01,\left[\mathrm{MnO}_{4}^{-}\right]=$ $4.0 \times 10^{-4},\left[H^{+}\right]=0.5$, and $I=1.0 \mathrm{~mol} \mathrm{dm} m^{-3}$ at $25^{\circ} \mathrm{C}$.

In general, reduction of permanganate in acid medium goes to either $\mathrm{Mn}(\mathrm{II})$ or $\mathrm{Mn}(\mathrm{IV})$, where the reduction potential of the $\mathrm{Mn}(\mathrm{VII}) / \mathrm{Mn}(\mathrm{II})$ couple is $1.51 \mathrm{~V}$ and of the $\mathrm{Mn}(\mathrm{VII}) / \mathrm{Mn}(\mathrm{IV})$ couple is $1.695 \mathrm{~V}$ [36] according to the following equations:

$$
\mathrm{MnO}_{4}{ }^{-}+8 \mathrm{H}^{+}+5 \mathrm{e}=\mathrm{Mn}^{2+}+4 \mathrm{H}_{2} \mathrm{O}
$$

and in the presence of an excess of permanganate ion, the product is $\mathrm{MnO}_{2}$ :

$$
2 \mathrm{MnO}_{4}{ }^{-}+3 \mathrm{Mn}^{2+}+2 \mathrm{H}_{2} \mathrm{O}=5 \mathrm{MnO}_{2}+4 \mathrm{H}^{+}
$$

Manganese(VII) $\left(\mathrm{MnO}_{4}^{-}\right)$is reduced to $\mathrm{Mn}(\mathrm{II})$ during oxidation processes via many manganese intermediate species having different oxidation states such as $\mathrm{Mn}(\mathrm{VI})$, $\mathrm{Mn}(\mathrm{V}), \mathrm{Mn}(\mathrm{IV})$ and $\mathrm{Mn}(\mathrm{III})$. On the other hand, Mn(II), the ultimate reaction product, acts as an autocatalyst. The appearance of these intermediate oxidation states depends upon various reaction conditions, types of substrate and their stability. The manganese chemistry involved in these multistep redox reactions is an important source of information because the manganese intermediates are relatively easy to identify when they have a sufficiently long lifetimes, and the oxidation states of the intermediate species permit useful conclusions about possible reaction mechanisms, including the nature of the intermediates [15].

During the oxidation by permanganate ion in acid media, the intermediate $\mathrm{Mn}$ (IV) species may be formed which could be $\mathrm{H}_{2} \mathrm{MnO}_{4}, \mathrm{H}_{2} \mathrm{MnO}_{3}$ or a water-soluble colloidal $\mathrm{MnO}_{2}$ [15]. The $\mathrm{MnO}_{2}$ is unstable due to its reaction with acid producing $\mathrm{Mn}(\mathrm{II})$. The appearance of a new band at a wavelength of $418 \mathrm{~nm}$ suggests intervention of $\mathrm{Mn}(\mathrm{IV})$ [37, 38] as a reduced product of the oxidant. Also, Mn(IV) formation may be due to the reaction between $\mathrm{Mn}(\mathrm{V})$ and
$\mathrm{Mn}(\mathrm{III})$.

The sigmoid profile, observed in the reaction-time curves gives a conclusive evidence for an autocatalytic oxidation process in acidic medium in which $\mathrm{Mn}$ (II) species are responsible for this effect. As the reactions are of catalytic nature, they obey the rate expression: $\left(\mathrm{A}_{\mathrm{t}}-\mathrm{A}_{\infty}\right)=\mathrm{B}_{\mathrm{o}} \mathrm{e}^{-k \mathrm{st}}+$ $\mathrm{P}_{\mathrm{o}} \mathrm{e}^{-k f t}$ [39] where $k_{\mathrm{s}}$ and $k_{\mathrm{f}}$ are the first order rate constants for the slow (induction) and fast (auto-acceleration) periods, $\mathrm{A}_{\mathrm{t}}$ and $\mathrm{A}_{\infty}$ are the absorbance at times $t$ and infinity; while $\mathrm{B}_{\mathrm{o}}$ and $\mathrm{P}_{\mathrm{o}}$ represent the absorbance change for the slow and fast reacting species, respectively. The rate constants were obtained by drawing a straight line through the slow-time linear portion $\left(k_{\mathrm{s}}\right)$ of the first order plot and extrapolating the time back to zero time $\left(\mathrm{B}_{\mathrm{o}}\right)$. The rate of oxidation for the auto-acceleration period, $k_{\mathrm{f}}$, was obtained from plots of $\ln \left[\left(A_{t}-A_{\infty}\right)-\left(A_{\infty}-A_{t}\right)\right]$ versus $t$ where the quantity $\left(A_{t}-\right.$ $\left.A_{\infty}\right)$ represents the experimental point and $\left(A_{\infty}-A_{t}\right)$ is the extrapolated one at time $t$. Similar redox reactions involving permanganate as an oxidant, which followed the same behavior, were reported elsewhere [40, 41].

Since $\mathrm{Mn}^{2+}$ is one of the oxidation products of permanganate ion in acid media, its effect on the reaction rate should be examined. It is well known [42] that acidified permanganate is reduced by addition of $\mathrm{Mn}^{2+}$ to give $\mathrm{Mn}^{3+}$ and $\mathrm{Mn}^{4+}$ according to the following equation

$$
\mathrm{MnO}_{4}{ }^{-}+3 \mathrm{Mn}^{2+}+8 \mathrm{H}^{+} \longrightarrow 3 \mathrm{Mn}^{3+}+\mathrm{Mn}^{4+}+4 \mathrm{H}_{2} \mathrm{O}
$$

where $\mathrm{Mn}^{3+}$ and $\mathrm{Mn}^{4+}$ can be removed by fluoride ions owing to the formation of stable complexes with these ions [40]. If $\mathrm{MnO}_{4}{ }^{-}$ion is primarily responsible for oxidation, a reduction in the initial rate should be observed in the presence of $\mathrm{Mn}^{2+}$ ions which reduce the concentration of permanganate ions [43]. If the intermediates $\mathrm{Mn}^{3+}$ and/or $\mathrm{Mn}^{4+}$ are the reactive oxidizing species, addition of $\mathrm{Mn}^{2+}$ should accelerate the reaction rate. Similarly, addition of $\mathrm{F}^{-}$ions should retard the rate of reaction if the intermediate manganese(III) and/or manganese(IV) ions are the mainly responsible for the oxidation and cause no significant change if $\mathrm{MnO}_{4}{ }^{-}$ions are the principle oxidizing entities. Furthermore, the catalytic effect of $\mathrm{Mn}^{2+}$ may be attributed to the formation of a complex with the substrate which is then oxidized by $\mathrm{HMnO}_{4}$.

The obtained results showed a notable increase in the reaction rate upon initial addition of $\mathrm{Mn}(\mathrm{II})$ ion to the reaction medium as illustrated in Figure 5(a). Also, further increase in initial $\mathrm{Mn}(\mathrm{II})$ concentration and maintaining the $\mathrm{Mn}(\mathrm{II})$ concentration equal to the permanganate ion concentration led to a complete disappearance of the sigmoid form. The complete disappearance of the sigmoid form as well as the decrease in the reaction rate upon the addition of fluoride ion, Figure 5(b), may suggest that $\mathrm{Mn}$ (III) and/or $\mathrm{Mn}(\mathrm{IV})$ are the principle reactive species in the fast final period.

Many investigators [34, 35, 44-46] have suggested that permanganate ion in acid media tends to protonate to form a more powerful species, namely permanganic acid according to the following equilibrium: 


$$
\mathrm{MnO}_{4}{ }^{-}+\mathrm{H}^{+} \stackrel{K_{1}}{\rightleftharpoons} \mathrm{HMnO}_{4}
$$

where $K_{1}$ is the protonation constant of permanganate ion. The protonation of permanganate ion shifts the $\mathrm{Mn}^{\mathrm{VII}} / \mathrm{Mn}^{\mathrm{VI}}$ couple to a more positive value $(+1.3 \mathrm{~V})$, which makes $\mathrm{HMnO}_{4}$ a stronger oxidizing agent than $\mathrm{MnO}_{4}^{-}$. The observed enhancement of the reactions rates with increasing hydrogen ion concentrations supports this suggestion.

The present reactions between permanganate ion and caffeine in both perchloric and sulfuric acid solutions have 2: 5 stoichiometry $\left(\mathrm{MnO}_{4}^{-}: \mathrm{CAF}\right)$, with first order dependences on both substrate and oxidant and an apparent less than unity order with respect to the acids concentrations. In view of the above arguments, the reactions mechanism for which all the observed orders in each constituent, such as [oxidant], [reductant] and $\left[\mathrm{H}^{+}\right]$, are well accommodated is suggested and illustrated in Scheme 1. The mechanism involves attack of the powerful oxidant, acid permanganate, on the first mole of caffeine substrate in the rate determining step to give a free radical derived from caffeine and an intermediate $\mathrm{Mn}(\mathrm{VI})$ species. The observed insignificant effect of either ionic strength or dielectric constant of the medium on the

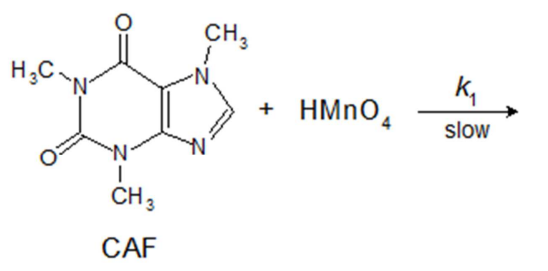

reactions rates implies association of two neutral molecule $[47,48]$, i.e. between caffeine and acid permanganate. Then, he intermediate $\mathrm{Mn}(\mathrm{VI})$ reacts with a free radical, producing 8-hydroxy caffeine which tautemerise to the final oxidation product of caffeine, 1,3,7-trimethyluric acid (TMU). In a further fast step the intermediate $\mathrm{Mn}(\mathrm{V})$, being very active and unstable in acid medium, reacts with another mole of caffeine to form again TMU product and an intermediate $\mathrm{Mn}(\mathrm{III})$ species. Similar to the previous two steps, other two moles of caffeine substrate react with acid permanganate species to form again two moles of TUU product and Mn(III) species. The last step is the rapidly attack of the two formed $\mathrm{Mn}$ (III) intermediate species on another caffeine mole of caffeine to give the last TMU product and the final oxidation product of permanganate, $\mathrm{Mn}(\mathrm{II})$, satisfying the obtained stoichiometry. The failure of spectroscopic detection of the proposed intermediate $\mathrm{Mn}(\mathrm{V})$ and $\mathrm{Mn}(\mathrm{III})$ species as the reaction proceeded may be interpreted by its extreme short lifetime which undergoes a rapid disproportionation or due to the low concentrations of $\mathrm{Mn}(\mathrm{V})$ and $\mathrm{Mn}(\mathrm{III})$ intermediates obtained under our experimental conditions. However, there are reports in the literature for the existence of $\mathrm{Mn}(\mathrm{V})$ and $\mathrm{Mn}(\mathrm{III})$ [46].<smiles>Cn1c(=O)c2c(nc(C=COC(C)(C)C)n2C)n(C)c1=O</smiles><smiles>C=CC=CC=C</smiles><smiles>Cn1c(=O)c2c(nc(O)n2C)n(C)c1=O</smiles>

TMU<smiles>Cn1c(=O)c2c(nc(NO[GaH2])n2C)n(C)c1=O</smiles><smiles></smiles>

2<smiles>Cn1c(=O)c2c([nH]c(=O)n2C)n(C)c1=O</smiles>

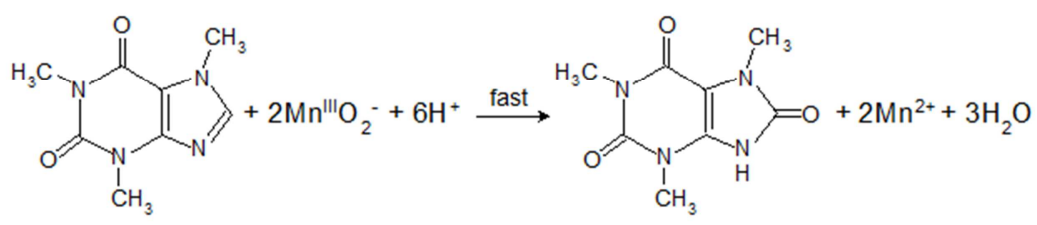

Scheme 1. Mechanism of oxidation of caffeine by permanganate ion in acid media. 
According to the proposed mechanistic Scheme 1, the oxidation rate can be expressed by the following rate law:

$$
\begin{aligned}
& \text { Rate }=\frac{-d\left[\mathrm{MnO}_{4}^{-}\right]}{d t}=k_{1}[\mathrm{CAF}]\left[\mathrm{HMnO}_{4}\right] \\
& K_{1}=\frac{\left[\mathrm{HMnO}_{4}\right]}{\left[\mathrm{MnO}_{4}^{-}\right]\left[\mathrm{H}^{+}\right]},\left[\mathrm{HMnO}_{4}\right]=K_{1}\left[\mathrm{MnO}_{4}^{-}\right]\left[\mathrm{H}^{+}\right]
\end{aligned}
$$

Substituting Eq. (2) into Eq. (1) leads to:

$$
\text { Rate }=k_{1} K_{1}[\mathrm{CAF}]\left[\mathrm{MnO}_{4}^{-}\right]\left[\mathrm{H}^{+}\right]
$$

The total concentration of $\mathrm{MnO}_{4}{ }^{-}$is given by:

$$
\left[\mathrm{MnO}_{4}^{-}\right]_{\mathrm{T}}=\left[\mathrm{MnO}_{4}^{-}\right]_{\mathrm{F}}+\left[\mathrm{HMnO}_{4}\right]
$$

where ' $\mathrm{T}$ ' and ' $\mathrm{F}$ ' stand for total and free concentrations.

Therefore,

$$
\begin{aligned}
{\left[\mathrm{MnO}_{4}^{-}\right]_{\mathrm{T}} } & =\left[\mathrm{MnO}_{4}^{-}\right]_{\mathrm{F}}+K_{1}\left[\mathrm{MnO}_{4}^{-}\right]_{\mathrm{F}}\left[\mathrm{H}^{+}\right] \\
{\left[\mathrm{MnO}_{4}^{-}\right]_{\mathrm{F}} } & =\frac{\left[\mathrm{MnO}_{4}^{-}\right]_{\mathrm{T}}}{1+K_{1}\left[\mathrm{H}^{+}\right]}
\end{aligned}
$$

Substituting Eqs. (6) into Eq. (3) (and omitting 'T' and ' $F$ ' subscripts) leads to:

$$
\text { Rate }=\frac{k_{1} K_{1}\left[\mathrm{MnO}_{4}^{-}\right][\mathrm{CAF}]\left[\mathrm{H}^{+}\right]}{1+K_{1}\left[\mathrm{H}^{+}\right]}
$$

Under pseudo-first order condition, the rate-law can be expressed by equation (8):

$$
\text { Rate }=\frac{-d\left[\mathrm{MnO}_{4}^{-}\right]}{d t}=k_{s}\left[\mathrm{MnO}_{4}^{-}\right]
$$

Comparing Eqs. (7) and (8), we get the following relationship:

$$
k_{s}=\frac{k_{1} K_{1}[\mathrm{CAF}]\left[\mathrm{H}^{+}\right]}{1+K_{1}\left[\mathrm{H}^{+}\right]}
$$

With rearrangement of Eq. (9), the following equation is obtained:

$$
\frac{[\mathrm{CAF}]}{k_{s}}=\frac{1}{k_{1} K_{1}\left[\mathrm{H}^{+}\right]}+\frac{1}{k_{1}}
$$

According to Eq. (10), other conditions being constant, a plot of $[\mathrm{CAF}] / k_{\mathrm{s}}$ versus $1 /\left[\mathrm{H}^{+}\right]$is expected to be linear and is found to be so (Figure 7). The slope and intercept of this plot yield values of $K_{1}$ and $k_{1}$ at $25^{\circ} \mathrm{C}$. This value of $K_{1}$ is in agreement with the literature $[35,49]$.

The activation parameters listed in Table 2 may be interpreted as follows. The obtained positive values of $\Delta S^{t}$ suggest that the reactions point towards the outer-sphere pathway [50]. The positive values of both $\Delta H^{\neq}$and $\Delta G^{\neq}$ confirm endothermic formation of the intermediate complexes and their non-spontaneities, respectively.

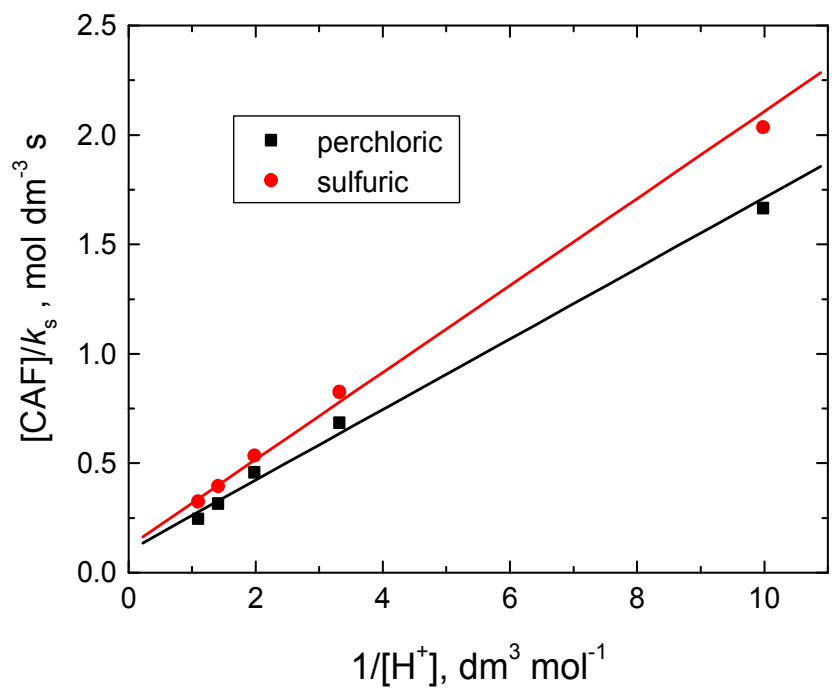

Figure 7. Verification of equation (5) for the oxidations of caffeine by permanganate ion in perchloric and sulfuric acids solutions. $\left[\mathrm{MnO}_{4}^{-}\right]=4.0$ $\times 10^{-4}$ and $I=1.0 \mathrm{~mol} \mathrm{dm}^{-3}$ at $25^{\circ} \mathrm{C}$.

Table 3. Values of $k_{1}$ and $K_{1}$ in the oxidations of caffeine by permanganate ion in perchloric and sulfuric acids solutions at $25^{\circ} \mathrm{C}$.

\begin{tabular}{lll}
\hline Acid & $\boldsymbol{k}_{\mathbf{1}}, \mathbf{d m}^{\mathbf{3}} \mathbf{~ m o l}^{-\mathbf{1}} \mathbf{s}^{-\mathbf{1}}$ & $\boldsymbol{K}_{\mathbf{1}}, \mathbf{d m}^{\mathbf{3}} \mathbf{~ m o l}^{-\mathbf{1}}$ \\
\hline Perchloric & 9.7 & 0.53 \\
Sulfuric & 9.1 & 0.51 \\
\hline
\end{tabular}

\section{Conclusions}

The kinetics of oxidations of caffeine by permanganate ion in both perchloric and sulfuric acids solutions has been studied. The main oxidation product of caffeine was identified in both cases as 1,3,7-trimethyluoric acid. Under comparable experimental conditions, the oxidation rate in perchloric acid was slightly higher than that in sulfuric acid. The reactions constants involved in the different steps of the oxidations mechanism along with the activation parameters have been evaluated and discussed.

\section{Acknowledgement}

The Authors are highly indebted to the Chemistry Department, Umm Al-Qura University for using of all instrumentation facilities.

\section{References}

[1] Kittakoop P, Mahidol C, Ruchirawat S (2014) Alkaloids as important scaffolds in therapeutic drugs for the treatments of cancer, tuberculosis, and smoking cessation. Curr. Top. Med. Chem. 14: 239-252.

[2] Cushnie TP, Cushnie B, Lamb AJ (2014) Recent advances in understanding the antibacterial properties of flavonoids. Int. J. Antimicrob. Agents 44: 377-386. 
[3] Qiu S, Sun H, Zhang AH, Xu HY, Yan GL, Han Y, Wang XJ (2014) Natural alkaloids: basic aspects, biological roles, and future perspectives. Chin. J. Nat. Med. 12: 401-406.

[4] Ashihara H, Crozier A (2001) Caffeine: a well-known but little mentioned compound in plant science. TRENDS Plant Sci. 6: 407-413

[5] Parliment TH, Ho CT, Schieberle P (2000) Caffeinated Beverages: Health Benefits, Physiological Effects, and Chemistry. American Chemical Society symposium series ISSN 0097-6156; 754.

[6] Nehlig A, Daval JL, Debry G (1992) Caffeine and the central nervous system: mechanisms of action, biochemical, metabolic and psychostimulant effects. Brain Res. Brain Res. Rev. 17: 139-70.

[7] Bolton S (1981) Caffeine: Psychological Effects, Use and Abuse.Orthomolecular Psychiatry 10: 202-211.

[8] Snel J, Lorist MM (2011) Effects of caffeine on sleep and cognition. Prog. Brain Res. Progress in Brain Research 190: $105-17$.

[9] Bishop D (2010) Dietary supplements and team-sport performance. Sports Med. 40: 995-1017.

[10] Conger SA, Warren GL, Hardy MA, Millard-Stafford ML (2011) Does caffeine added to carbohydrate provide additional ergogenic benefit for endurance. Int. J. Sport Nut. Exerc. Metab. 21: 71-84.

[11] Astorino TA, Roberson DW (2010) Efficacy of acute caffeine ingestion for short-term high-intensity exercise performance: a systematic review. J. Strength Cond. Res. 24: 257-65.

[12] Nehlig A (2010) Is caffeine a cognitive enhancer? J. Alzheimers Dis. 20 Suppl. 1: S85-94.

[13] Weinberg BA, Bealer BK (2001) The world of caffeine: the science and culture of the world's most popular drug. Routledge Publication, New York.

[14] Escohotado A, Symington K (1999) A Brief History of Drugs: From the Stone Age to the Stoned Age. Park Street Press.

[15] Stewart R (1965) Oxidation in Organic Chemistry, Part A (ed.) Wiberg KB, New York, Academic Press.

[16] Jose TP, Nandibewoor ST, Tuwar SM (2005) Mechanism of oxidation of L-histidine by heptavalent manganese in alkaline medium. E-J. Chem. 2: 75-85.

[17] Fawzy A, Ashour S, Musleh MA (2014) Base-catalyzed oxidation of L-asparagine by alkaline permanganate and the effect of alkali-metal ion catalysts: kinetics and mechanistic approach. React. Kinet. Mech. Catal. 111: 443-460.

[18] Fawzy A, Shaaban MR (2014) Kinetic and mechanistic investigations on the oxidation of N'-heteroaryl unsymmetrical formamidines by permanganate in aqueous alkaline medium. Transition Met. Chem. 39: 379-386.

[19] Fawzy A, Zaafarany IA, Alfahemi J, Tirkistani FA (2015) Base-catalyzed oxidation of aminotriazole derivative by permanganate ion in aqueous alkaline medium: a kinetic study. Int. J. Inn. Res. Sci. Eng. Tech., 4: 6802-6814.

[20] Asghar BH, Fawzy A (2014) Kinetic, mechanistic, and spectroscopic studies of permanganate oxidation of azinylformamidines in acidic medium, with autocatalytic behavior of manganese (II). J. Saudi Chem. Soc., in press.
[21] Fawzy A, Ashour SS, Musleh MA (2014) Kinetics and mechanism of oxidation of L-histidine by permanganate ions in sulfuric acid medium. Int. J. Chem. Kinet. 46: 370-381.

[22] Ahmed GA, Fawzy A, Hassan RM (2007) Spectrophotometric evidence for the formation of short-lived hypomanganate $(\mathrm{V})$ and manganate(VI) transient species during the oxidation of $K$-carrageenan by alkaline permanganate. Carbohydr. Res., 342: 1382-1386.

[23] Zaafarany IA, Fawzy A, Ahmed GA, Ibrahim SA, Hassan RM, Takagi HD (2010) Further evidence for detection of short-lived transient hypomanganate(V) and manganate(VI) intermediates during oxidation of some sulfated polysaccharides by alkaline permanganate using conventional spectrophotometeric techniques. Carbohydr. Res., 345: 1588-1593.

[24] Hassan RM, Fawzy A, Alarifi A, Ahmed GA, Zaafarany IA, Takagi HD (2011) Base-catalyzed oxidation of some sulfated macromolecules: kinetics and mechanism of formation of intermediate complexes of short-lived manganate (VI) and/or hypomanganate $(\mathrm{V})$ during oxidation of iota- and lambdacarrageenan polysaccharides by alkaline permanganate. J. Mol. Catal. A, 335: 38-45.

[25] Hassan RM, Dahy A, Ibrahim S, Zaafarany IA, Fawzy A (2012) Oxidation of some macromolecules. Kinetics and mechanism of oxidation of methyl cellulose polysaccharide by permanganate ion in acid perchlorate solutions. Ind. Eng. Chem. Res., 51: 5424-5432.

[26] Gardner KA, Kuehnert LL, Mayer JM (1997) Hydrogen atom abstraction by permanganate: oxidations of arylalkanes in organic solvents. Inorg. Chem., 36: 2069-2078.

[27] Perez-Benito JF (2011) Permanganate oxidation of $\alpha$-amino acids: kinetic correlations for the nonautocatalytic and autocatalytic reaction pathways. J. Phys. Chem. 115: 98769885.

[28] Babatunde OA (2008) A study of the kinetics and mechanism of oxidation L-ascorbic acid by permanganate ion in acidic medium. World J. Chem. 3: 27-31.

[29] Jayaram B, Mayanna SM (1983) Mechanism of oxidation of caffeine by sodium N-chlorobenzene: a kinetic study. Tetrahedron 39: 2271-2275.

[30] Souza FS, Féris LA (2015) Degradation of caffeine by advanced oxidative processes: $\mathrm{O}_{3}$ and $\mathrm{O}_{3} / \mathrm{UV}$, Ozone: Sci. Eng. 37: 379-384.

[31] Kumar M, Adinarayana M (2000) Oxidation of caffeine by phosphate radical anion in aqueous solution under anoxic conditions. J. Chem. Sci. 112: 551-557.

[32] Vogel I. A (1978) A Text book of quantitative inorganic analysis. $4^{\text {th }}$ edn ELBS and Longman, New York, pp. 352; Feigl F (1975) Spot tests in organic analysis, 195 pp. Elsevier, New York.

[33] Michaelis L, Menten ML (1913) The kinetics of invertase action. Biochem. Z. 49: 333-369.

[34] Zahedi M, Bahrami H (2004) Kinetic and mechanism of autocatalytic oxidation of L-asperagine in moderately concentrated sulphuric acid medium. Kinet. Catal. 45: 351-358.

[35] Hosahalli RV, Savanur AP, Nandibewoor ST, Chimatadar SA (2012) Kinetics and mechanism of the autocatalyzed oxidation of theophylline by permanganate in aqueous perchloric acid medium. J. Solution Chem. 41: 567-580. 
[36] Day MC, Selbin J (1985) Theoretical Inorganic Chemistry, Reinhold Publishing Corporation, New York, 1985, pp. 344.

[37] Perez Benito JF, Mata Perez F, Brillas E (1987) Permanganate oxidation of glycine: Kinetics, catalytic effects, and mechanisms. Can. J. Chem. 65: 2329-2337.

[38] Garrido JA, Perez Benito JF, Rodrigouez RM, Andrés JDe, Brillas E (1987) Autocatalysis by colloidal manganese dioxide in the permanganate oxidation of L-isoleucine. J. Chem. Res. 11: $380-381$.

[39] Abdel-Hamid MI, Khairou KS, Hassan RM (2003) Kinetics and mechanism of permanganate oxidation of pectin in acid perchlorate media. Eur. Polym. J. 39: 381-387.

[40] Girgis MM, El-Shatoury SA, Khalil ZA (1985) Kinetics and mechanism of oxidation of lactic acid by $\mathrm{KMnO}_{4}$ in $\mathrm{H}_{2} \mathrm{SO}_{4}$ medium. Can. J. Chem. 63: 3317-3321.

[41] Hassan RM, Fawzy A, Ahmed GA, Zaafarany IA, Asghar BS, Khairou KS (2009) Acid-catalyzed oxidation of some sulfated macromolecules. Kinetics and mechanism of oxidation of kappa-carrageenan polysaccharide by permanganate ion in acid perchlorate solutions. J. Mol. Catal. A: Chem. 309: 95102.
[42] Waters WA (1958) Rev. Chem. Soc. 12: 277-281.

[43] Launer HF (1932) J. Am. Chem. Soc. 54: 2297-2302.

[44] Wiberg KB (1965) Oxidation in Organic Chemistry, Part A, $48 \mathrm{pp}$. Academic Press, New York.

[45] Chimatadar SA, Hiremath SC, Raju JR (1990) Oxidation of thallium (I) by permanganate in aqueous perchloric acid medium. Indian J. Chem. 30A: 190-192.

[46] Bailar JC, Emeleus HJ, Nyholm R, Dickenson AFT (1975) Comprehensive Inorganic Chemistry, pp. 771, Pergamon Press Ltd., New York.

[47] Frost AA, Person RG (1970) Kinetics and mechanism, Wiley Eastern, New Delhi, pp. 147.

[48] Laidler K (1965) Chemical kinetics. McGraw-Hill, New York.

[49] Farokhi SA, Nandibewoor ST (2004) The kinetic and mechanism of the oxidative decarboxylation of benzilic acid by acid permanganate (stopped flow technique) - autocatalytic study. Can. J. Chem. 82: 1372-1380.

[50] Weissberger A (1974) In Investigation of rates and mechanism of reactions in techniques of chemistry, John Wiley \& Sons (New York: Interscience Publication) pp. 421. 